\title{
Representaciones, roles, y resistencias, de las mujeres en contextos de violencia
}

Representations, Roles and Resistances of Women in Contexts of Violence

Représentations, rôles et résistances des femmes en contexte de violence

\section{Carmen Magallón Portolés}

\section{OpenEdition}

\section{Journals}

Edição electrónica

URL: http://journals.openedition.org/rccs/4797

DOI: $10.4000 /$ rccs. 4797

ISSN: 2182-7435

\section{Editora}

Centro de Estudos Sociais da Universidade de Coimbra

Edição impressa

Data de publição: 1 Março 2012

Paginação: 09-30

ISSN: 0254-1106

Refêrencia eletrónica

Carmen Magallón Portolés, «Representaciones, roles, y resistencias, de las mujeres en contextos de violencia », Revista Crítica de Ciências Sociais [Online], 96 | 2012, colocado online no dia 15 fevereiro 2013, criado a 30 abril 2019. URL : http://journals.openedition.org/rccs/4797 ; DOI : 10.4000/ rccs. 4797 


\title{
CARMEN MAGALLÓN PORTOLÉS
}

\section{Representaciones, roles, y resistencias, de las mujeres en contextos de violencia}

\begin{abstract}
Partiendo de que todo conocimiento es situado, el artículo subraya la importancia de pensar desde las vidas de los grupos excluidos, en este caso las mujeres, para llenar los silencios y olvidos de las disciplinas. Tomando como base la epistemología del Feminist Standpoint, repasa distintas representaciones y miradas que los hombres proyectan sobre las mujeres en contextos de violencia y que influyen en su modo de tratarlas, nacidas de estereotipos y estructuras de dominio, sexuales y culturales. Repasa también las construcciones que las mujeres hacen de sí mismas, así como la diversidad de sus opciones ante la violencia. Sin negar su complicidad en el mantenimiento del imaginario masculino estereotipado ni su corresponsabilidad en el ejercicio de la violencia, la autora busca destacar las imágenes y fortalezas que ellas construyen de manera más autónoma.
\end{abstract}

Palabras clave: estudios de género; guerra; violencia; victimación.

Palavras-chave: estudos sobre a mulher; guerra; violência; vitimação.

\section{Introducción}

$\mathrm{Al}$ iniciar este trabajo me doy cuenta de que no puedo hablar de las mujeres en las guerras como si fuera un asunto que a mí no me hubiera rozado, cuando mi propia experiencia vital está llena de relatos, imágenes y lecturas de las que extraigo motivación y enseñanzas: imágenes de mi padre herido cerca de Teruel, en la Guerra Civil española (1936-1939) mientras defiende la legalidad republicana; imágenes de mi madre, tan joven, viviendo junto a soldados acuartelados; la imagen de mi tía Eusebia, asomada a una ventana de la casa de mis abuelos paternos diciendo: "está ardiendo todo menos esta casa" mientras la aviación alemana al servicio de Franco bombardea nuestro pequeño pueblo del Bajo Aragón...

De estas y otras imágenes, extraídas de los relatos de la guerra oídos en mi infancia, surgen enseñanzas que rompen ciertos estereotipos sobre hombres y mujeres, en relación con la violencia: aquellos en los que a ellas 
se les atribuye el lugar de las víctimas. Porque pienso en mis dos abuelas desafiando a las distintas autoridades que fueron tomando el pueblo, ya sea por defender a un preso, ya por dar de comer a unos y otros en la alejada casa de labranza, sin mirar el color y el bando; y las veo como mujeres empoderadas y con determinación. Y es la figura de mi padre, un joven obligado a tomar las armas e ir al frente, con sus escasos 18 años, la que emerge claramente como víctima: teniendo que acatar las decisiones que otros tomaron por él, y que supusieron, entre la guerra y el servicio militar posterior obligatorio para los soldados del bando perdedor, arruinar siete de sus mejores años.

También escuché contar sus historias a mujeres muy distintas: activistas por la paz, líderes políticas, líderes populares, perseguidas, exguerrilleras, agredidas, mujeres que pelean contra la impunidad de quienes mataron a sus familiares... Es la experiencia de estas vidas plurales y contradictorias, aunque con rasgos en común, la que late en el fondo de este trabajo, que se plantea reflexionar sobre la interacción entre representaciones, miradas e imágenes, $\mathrm{y}$ violencia.

\section{¿Desde dónde pensar?: la epistemología del Feminist Standpoint}

La racionalización del uso de la violencia ha sido una constante en la tradición de pensamiento Occidental que predica de sí mismo la objetividad y la universalidad. En ella, los grupos diferentes al arquetipo de hombre blanco, occidental, de clase media, fueron considerados menos que humanos lo que fue suficiente para convertirlos en invisibles y justificar la violencia desatada contra ellos. En el libro de Sven Lindqvist (2004) cuyo título provocador, Exterminad a todos los salvajes, muestra ya la dura lucidez de su contenido, tenemos un ejemplo. Se trata de un relato magnífico que invita a reflexionar sobre la relación entre las imágenes y construcción del Otro, y las conductas violentas hacia él. Recuerda Lindqvist las prácticas coloniales de los europeos en África, la expansión imperialista en ese continente conseguida a través del exterminio y la dominación de sus gentes; actuaciones derivadas del racismo que impregnaba su pensamiento: un pensamiento racional y con capacidad científica, que sin embargo era incapaz de ver el mal producido y justificaba la violencia bajo discursos de civilización. Algo análogo sucedió con las mujeres, que ya desde Aristóteles fueron conceptualizadas como varones defectuosos. Las nociones e imágenes construidas sobre 'la mujer' han justificado sistemáticamente su subordinación y las violencias ejercidas sobre ellas.

Esta relación entre discursos y violencia, empuja a pensar desde las perspectivas críticas que surgen de los grupos que fueron excluidos, 
cuya experiencia fue relegada en la construcción del conocimiento. La crítica del discurso dominante y del saber androcéntrico, eurocéntrico y dominador de la Naturaleza vino de la mano de los movimientos sociales levantados por los grupos excluidos, entre ellos, el feminismo, que cuestionaron la desigualdad y el maltrato, directo y simbólico, que encerraban las visiones de la realidad transmitidas por la corriente principal. La energía de los movimientos sociales puesta en juego en la indagación sobre lo que sucede en el mundo, se tradujo de hecho en la identificación y eliminación de sesgos en el conocimiento transmitido, y de este modo dio lugar a un conocimiento mejor (Harding, 1991; 1986; Magallón, 1999). Y es que un enfoque arraigado en la vida material de los grupos marginados genera interrogantes que ponen en cuestión el estado de cosas hegemónico: las preguntas que crecen en la exclusión poseen la energía crítica necesaria para la emergencia de enfoques de transformación.

Como Harding (1986), pienso que todo conocimiento es situado, es decir, arraiga en la experiencia de un grupo humano; que no existen los problemas en general, que algo es considerado un problema, en la vida pública o en el terreno académico, cuando tiene tras de sí un sujeto que lo considera como tal, un sujeto respaldado por un cierto consenso de grupo. Que este problema pase a ser relevante para otros grupos depende del poder y la influencia del grupo en cuestión, de su movilización, en el caso de los grupos excluidos.

Preguntémonos, por ejemplo, cuándo ha sido un problema la violación de las mujeres, ya sea en tiempos de guerra o en tiempos de paz. En el ámbito internacional, la violación durante la guerra sólo tomó entidad de problema cuando una red de mujeres organizadas, en la que jugaron un importante papel las Mujeres de Negro de Belgrado, testigos de su uso como arma de guerra en los países de la ex Yugoeslavia, logró que fuera reconocida como crimen de guerra en la Conferencia de Derechos Humanos celebrada en Viena en 1993. En cuanto a la violación en tiempo de paz, su paso a la consideración de problema público, aquí en España, es bastante reciente, y en muchos lugares del mundo todavía sigue siendo un asunto 'privado', un problema que no es visto como tal por sociedades y legislaciones de tradición patriarcal.

Una de las pioneras en la crítica del androcentrismo de las Relaciones Internacionales, J. Ann Tickner, ya en 1992 se preguntaba por qué la materia objeto de estudio en este campo estaba tan alejada de las vidas de las mujeres, se preguntaba también sobre la escasez de mujeres en su disciplina y sobre la ausencia de textos escritos por ellas en los enfoques tradicionales de la misma. Como sucedió en otros campos disciplinares, esta crítica supuso una mejora efectiva y una ampliación de la disciplina, ya que dio lugar 
a nuevas preguntas, y a visiones más inclusivas y holísticas. Otras autoras han hablado de los temas nunca tratados, de los silencios en las Relaciones Internacionales (Moura, 2010; Díez, 2010), vacíos que han existido pese a que difícilmente se puede conocer y explicar cabalmente el mundo en que vivimos sin tener en cuenta la experiencia de las mujeres, que elaborar conocimiento sin contar con la mitad de la humanidad genera visiones parciales y distorsionadas del mundo, de la política y de las relaciones de poder a todos los niveles (Youngs, 2004).

Los presupuestos de las epistemólogas del Feminist Standpoint son tomados como base y guía por investigadoras de distintos campos, también en Relaciones Internacionales. Según esta perspectiva, lo específico de estos análisis no radica en el método sino en las siguientes características: a) tomar las experiencias de las mujeres como fuente, nueva, de recursos teóricos y empíricos (no la propia experiencia vital sino las vidas plurales y fragmentadas de las mujeres); b) proponerse como objetivo la construcción de un conocimiento que sirva a las mujeres (y que también sirve a los hombres, ya que al hacer uso del concepto de género, que es una categoría relacional, se engloba a los hombres); c) colocar al sujeto investigador en el mismo plano crítico que el objeto investigado (lo que da lugar a la llamada objetividad fuerte) (Harding, 1991). La epistemología del Feminist Standpoint se sitúa en el post-positivismo, pone el acento más en las preguntas que en las justificaciones, se plantea por qué hay preguntas que no se hacen y actores que se invisibilizan, defiende la elaboración interdisciplinar del conocimiento y subraya la importancia que tienen los discursos para la construcción de la realidad (Tickner, 2006; Harding, 1986).

Esta perspectiva epistemológica es particularmente relevante para sacar a la luz cualquier aspecto de las vidas de las mujeres, ya que estas son tomadas como sistema de referencia para pensar; en especial, es relevante para hacer visibles identidades y violencias relegadas, fortalezas, resistencias, y la pluralidad negada en ellas.

\section{La proliferación de escenarios de violencia}

La violencia en el mundo se ha complejizado y está presente en múltiples escenarios, desplegándose en un continuum que difumina las fronteras entre la guerra y la paz. La guerra, como paradigma de violencia directa, ha cambiado su carácter de confrontación entre estados; las nuevas guerras (Kaldor, 2001) también han ido cambiando, se han fragmentado en confrontaciones entre grupos, en violencia dispersa, en acciones armadas a cargo de actores muy diversos; la violencia directa está presente en escenarios que antes eran lugares seguros, como es el caso de las ciudades, dando lugar a situaciones 
que han sido conceptualizadas como 'novísimas guerras' (Moura, 2010). La multiplicidad de escenarios violentos se ha hecho posible por la proliferación de armas ligeras, que sigue aumentando porque su comercio constituye un boyante negocio, y porque es capaz de esquivar los controles y protocolos establecidos para que no lleguen a zonas donde puedan ser usadas para violar los derechos humanos. En particular, es manifiesta la incidencia de la proliferación de armas ligeras en la violencia contra las mujeres o violencia de género, que es la ejercida por hombres con los que ellas mantienen o mantuvieron en algún momento un lazo de intimidad (Santos, 2009). Por el cese de esta producción letal trabajan organizaciones del mundo entero, objetivo que choca con los intereses de los países productores, entre ellos, y encabezando la lista de máximos vendedores, los cinco permanentes en el Consejo de Seguridad.

En el entramado de violencias dispersas que constituyen las novísimas guerras confluyen la violencia directa, la estructural y la cultural (Galtung, 2003), violencias que afectan de manera diferente a hombres y mujeres (Magallón, 2005). Una de las raíces más hondas y preocupantes de la violencia estructural está ubicada hoy en el pulso que la optimización financiera desregulada, es decir, la lógica del máximo beneficio, está echando al sistema de gobernanza global que nació tras la Segunda Guerra Mundial, el sistema de las Naciones Unidas, con todos sus logros y avances institucionales: la Declaración de Derechos Humanos, los distintos Tratados y Convenciones, la legislación internacional. La priorización del máximo beneficio se sitúa en el origen de las desigualdades crecientes entre distintas regiones del mundo, entre países, dentro de un mismo país, y aún dentro de una misma ciudad. Una consecuencia es el crecimiento de la desigualdad económica, que es vivida como una afrenta insufrible, sobre todo entre los jóvenes, expuestos a la influencia mediática, seductora e inalcanzable del consumo creciente: coches, viajes, aparatos electrónicos, toda una parafernalia que es símbolo de estatus elevado; problemática que no es ajena a la emergencia de la violencia en los suburbios de las megaciudades del mundo (Moura, 2012). En lugares donde a la desigualdad se une el narcotráfico, la violencia armada puede pasar a ser un signo de identidad para jóvenes sin alternativas (Santos, 2009).

La violencia estructural está infiltrada y contaminada por la criminalidad, el narcotráfico, el comercio de armas y el tráfico de personas, pues para quien no tiene acceso a la riqueza por las vías admitidas por el sistema, echar mano y adscribirse a grupos criminales es una tentación y, en según qué lugares, casi la única opción. Esta violencia deriva en violencia directa, ya sea en forma de sufrimiento y letalidad por la falta de recursos: situaciones de 
vida precarias y muerte por enfermedades curables, ya sea por la adscripción a grupos armados, sicarios y mafias que hieren y matan en escaramuzas urbanas, con frecuencia responsables de más muertes que los conflictos armados (Moura, 2010; 2012).

La violencia simbólica o cultural sigue presente y juega su papel en distintos niveles: se despliega en los escenarios internacionales, entre países, cuando unos señalan a otros como parte del eje del mal; se da dentro de un país, dentro de una ciudad, entre grupos de distintas creencias o procedencias, cuando las relaciones entre ellos están atravesadas por una jerarquía de valor, con desprecio del 'otro', un 'otro' susceptible de ser relegado en las opciones de empleo, promoción, educación -es el caso de tantos grupos de emigrantes en los países europeos-. Y se da entre los sexos y los géneros, cuando se reduce a mujeres y hombres a sus estereotipos, negando su capacidad de realización y proyección individual; o se devalúan las características consideradas femeninas, con independencia de que sean desplegadas en comportamientos por uno u otro sexo.

\section{Representaciones, marcos, miradas y comportamientos de mujeres en contextos de violencia}

Pese a que las mujeres han sido ligadas históricamente a la paz y los hombres a la guerra o la violencia, algunas historiadoras nos recuerdan que:

... no hay una simple contradicción de género entre la paz-mujer y la guerra-hombre. Hay situaciones intermedias. El hombre se aproxima e identifica también con un tipo de paz. La validación de la pax como un valor femenino es compartida inmediatamente con los personajes masculinos (hombres y dioses) como mediadores de tal principio. Baste recordar cómo el propio Marte es ensalzado como pacificador, al igual que el emperador, o el ejército. Del mismo modo, el género femenino se acerca simbólicamente a la guerra. En la exaltación de los ejércitos, está habitualmente presente en las representaciones la Victoria como una mujer. (Mirón et al., 2004: 380)

En un mundo donde hemos dejado de creer en las causas lineales y admitimos la complejidad del flujo de corrientes y campos de fuerza que nos tensionan, la realidad y lo que somos dentro de ella, las identidades y comportamientos, se mueven entre la fragilidad y el cierre integrista. La guerra, también en su vertiente novísima, juega un importante papel en la conformación de identidades de hombres y mujeres que conviven en los nuevos escenarios de violencia. Aunque es cierto que los roles de género se intensifican en la guerra y en medio de la violencia (Magallón, 1998; Goldstein, 2001), mujeres y hombres practican y sufren la violencia desde 
posiciones y roles que se han diversificado, aunque exista continuidad con las líneas simbólicas del pasado.

En las nuevas identidades siguen influyendo las creencias, expectativas y proyecciones enraizadas en las distintas tradiciones culturales, los modos de ser hombre y mujer recreados por las obras literarias y fílmicas, el arte y el pensamiento de un amplio abanico de idiosincrasias culturales. Pero en la conformación del universo simbólico ligado a los sexos, la novedad es el creciente impacto de las nuevas tecnologías de la comunicación, las redes informáticas y los medios de comunicación globalizados, que con su carga de representaciones e imágenes llegan de cualquier rincón del mundo y entran en cualquier rincón del mismo, fragiliza la identidad, alimenta deseos y frustraciones, aumenta la plasticidad y capacidad de cambio pero también los fundamentalismos que dan seguridad. En los contextos violentos actuales surgen nuevas masculinidades y feminidades, que siguen invisibilizándose cuando no concuerdan con los estereotipos tradicionales (Moura, 2010).

Dentro de esa fragilidad identitaria, vivida a veces como rigidez, el marco contextual puede dar lugar a representaciones que trastocan los comportamientos. Las acciones de hombres y mujeres vienen precedidas de una imagen, una representación de la que se derivará su comportamiento, representación que se elabora a partir de los discursos sociales dominantes y que cambia según las circunstancias. Ellas y ellos pueden verse a sí mismos, y ver al otro sexo, de modo diferente, según contextos. La plasticidad de comportamientos afecta a ambos sexos, aunque no siempre en la misma dirección. El rol masculino, estereotipado como dominador, puede extremarse en condiciones violentas; y el rol femenino, ligado estereotipadamente al rechazo de la violencia, diluirse, en situaciones de agresión extrema.

En su estudio sobre la interacción entre guerra y género, Goldstein (2001) concluye que matar no es algo natural ni para hombres ni para mujeres y que son las necesidades del sistema de guerra (Reardon, 1996) las que modulan sus comportamientos. En cualquier caso, cantidad de ejemplos ponen de manifiesto que siempre hay un resto de libertad individual con capacidad de expresarse fuera del rol estereotipado, también en situaciones extremas: un hombre puede comportarse de forma compasiva en medio de una guerra cruel, como ejemplifica el personaje de El pianista, capaz de dejarse humanizar por el enemigo, a través de la música; y una mujer comportarse con furia y violencia, como es el caso de la protagonista que sufre una violación y que, finalmente, mata a su violador, en la película Thelma y Louise.

Ciñéndome al análisis de representaciones e imágenes construidas sobre las mujeres en contextos de violencia, distinguiré entre representaciones construidas desde fuera, y las que expresan sus fortalezas y resistencias. 
En ambos casos, se trata de miradas y proyecciones complejas, dinámicas y hasta contradictorias, aunque con un curso de acción, con cierto margen de opción.

\section{Sobre cómo ven los hombres a las mujeres en escenarios de violencia}

Desde una mirada de mujer, que mira cómo los hombres miran a las mujeres, puede verse que en medio de las novísimas guerras, ellos pueden proyectar sobre los cuerpos de las mujeres distintas representaciones e imágenes, lo que en general acabará condicionando la forma de tratarlas. El poder de las imágenes y del simbolismo es enorme. Pueden verlas como objeto de placer o esclavas sexuales, como tierra enemiga para conquistar o tierra propia para proteger, como guerreras o compañeras de armas, como madres, hijas o esposas, como vírgenes o mujeres sagradas... En lo que sigue, sin ánimo exhaustivo, presento algunas de estas representaciones.

\section{Las mujeres como cuerpo violable}

De entre todas las representaciones de mujeres, elaboradas por hombres en situaciones de violencia (y aún de paz), la más persistente, la que es reconocible en distintas geografías y universos culturales, es la que identifica a las mujeres con su cuerpo como objeto de placer, la que las reduce a ser 'un cuerpo violable', según expresión de Elena Grau. En la guerra de la ex Yugoeslavia, ante las noticias de la violación sistemática de las mujeres por uno y otro lado, E. Grau escribió:

Desde hace semanas la presencia de mi cuerpo sexuado de mujer se acentúa con las punzadas del miedo y la cólera. Son las niñas/mujeres violadas y asesinadas que aparecen en cualquier rincón de nuestro país. Son las mujeres violadas y obligadas a parir niños serbios o croatas. Somos nosotras, mujeres que vivimos en un cuerpo violable. (1993: 47)

La violación en tiempos de guerra es una experiencia común que narran las mujeres de distintos países y culturas. Mujeres de Liberia, Somalilandia, Tigré, Uganda, Sri Lanka, India, Vietnam, El Salvador, Nicaragua, Croacia, Bosnia y Líbano, dieron su testimonio en la investigación llevada a cabo por el Panos Institute. Según esta investigación, en medio del conflicto armado, las mujeres desplegaron roles muy distintos: unas se identificaban con la guerra en su país, otras no; unas habían tomado las armas, otras no... pero todas hablaron de la violencia sexual que se desató contra ellas (Panos Institute, 1995; Magallón, 2002). La violación de las mujeres por los hombres tiene en los conflictos armados con un componente de limpieza étnica la 
característica añadida de ser un arma de guerra. Violar a las mujeres pasa a ser un signo de conquista, se posee el cuerpo de la mujer como tierra enemiga en la que se deposita la semilla propia, un signo de poder y también de humillación de los enemigos, pues muchas culturas ligan la integridad de las mujeres con el honor de los hombres. Estas representaciones de la mujer como objeto sexual o como tierra, ajena o propia, iguala a las mujeres de los distintos bandos, pues la violación se ejerce también contra las mujeres del propio grupo: compañeras en el ejército, en la guerrilla o en el grupo armado (Vázquez et al., 1996).

Una vertiente semi-institucionalizada (por la permisividad con que se acepta y a veces hasta se promueve) que pone en juego la figura de la mujer como 'cuerpo violable', es la explotación sexual de mujeres confinadas en establecimientos dedicados a este negocio. Es paradigmático el caso de las llamadas 'mujeres confort', nombre suavizado eufemísticamente para nombrar la esclavitud sexual de mujeres de Corea, China, Japón, Filipinas y otros países, que fueron forzadas a trabajar en burdeles para los soldados japoneses en la Segunda Guerra Mundial. Históricamente, en la explotación sexual de las mujeres han participado hombres de todo tipo. Y este abuso continúa hoy. Un informe realizado en 2004 en la República Democrática del Congo, hizo saltar todas las alarmas: los cascos azules en misión de mantenimiento de la paz se aprovechaban de la situación comprando sexo a mujeres que necesitaban comer. Organizaciones internacionales de mujeres llevan años denunciando estos hechos ante Naciones Unidas, que sólo recientemente proclamó su política de tolerancia cero.

En torno a las bases militares estadounidenses establecidas en distintos lugares del mundo crecen los establecimientos de prostitución (Enloe, 1989), pero también en ciudades donde hay paz, al menos ausencia de guerra, son negocios en alza. Particularmente preocupantes son las redes de tráfico en las que se engaña a las mujeres y se les retiene en burdeles contra su voluntad bajo amenaza de muerte, algo que sucede en mayor medida en zonas de posconflicto armado, donde las estructuras de gobierno siguen siendo frágiles. La película The Whistleblower recoge un caso real de implicación de oficiales de los cascos azules en el encubrimiento de una trama de tráfico de mujeres, en la Bosnia-Herzegovina de los años posteriores a la guerra que sufrió ese país.

Comportamientos denigrantes tan repetidos, protagonizados por hombres del común, militares y no militares, nos llevan a preguntarnos sobre el proceso que hace posible que hombres que pueden ser ciudadanos respetuosos con las normas, es decir normales, cierren los ojos y no se pregunten sobre la procedencia y problemática de las mujeres retenidas en 
estos espacios de explotación sexual. ¿Tienen capacidad algunos contextos para desatar representaciones de las mujeres que empujan a desvalorizarlas y explotarlas? ¿Qué papel legitimador juegan las complicidades entre los propios hombres? ¿Se dan complicidades de las propias mujeres?

Sobre por qué unas vidas son más valoradas que otras, Judith Butler (2006; 2010) escribe que lo que se permite pensar viene delimitado por un marco, un marco construido por la propaganda del poder, los medios de comunicación, las imágenes transmitidas, por la presión del grupo y las circunstancias contextuales: guerra, situación límite, acuartelamiento, violencia cruda, uso de armas, ruptura con la cotidianidad. La noción de 'marcos de pensamiento' explica muy bien cómo al mostrar una parte de la realidad y dejar fuera otra, determinados marcos nos llevan a la devaluación de las vidas de los otros, a que, por ejemplo, las vidas de los niños palestinos muertos bajo las bombas parezcan menos valiosas que las de los soldados israelíes muertos en combate. Análogamente, determinadas circunstancias, determinados espacios, los burdeles, por ejemplo, generan una representación de las mujeres que lleva a los hombres a reducirlas a cuerpos sexuados de usar y tirar, los lleva a convertirse en prostituidores y, en algunos casos, como en el contado en The Whistleblower, en asesinos.

La violación, en conflictos armados, en las calles de las ciudades o en el seno de las relaciones de pareja, es la expresión más prototípica de conducta masculina de dominación; y los burdeles, además de un lucrativo negocio, son un refugio para la expresión de esta dominación en contextos de permisividad. En ellos se asiste a un ritual de complicidades entre hombres de toda edad y condición, que acuden allí dentro de la más absoluta normalidad: tras una escaramuza armada, tras un congreso, para sellar un acuerdo financiero o para celebrar un cumpleaños (López Insausti y Baringo, 2006).

\section{Las mujeres como madres, como refugio, como bálsamo}

Independientemente de la pertenencia a un grupo armado, regular o irregular, de su comportamiento más o menos violento, y de su ubicación, un hombre sigue manteniendo determinadas representaciones como símbolos idealizados de mujer, símbolos que son tomados como sagrados: puede ser la figura de la virgen, si es católico; la de la madre, de la hija, de la esposa; la figura de la enfermera. A través de relatos biográficos conocemos cómo en la vida de personajes despiadados, pandilleros, narcotraficantes, mafiosos, soldados y guerreros endurecidos por las acciones violentas, hay determinadas figuras de mujer respetadas y protegidas. Son imágenes que evocan la propia vulnerabilidad y el papel que se atribuye a las mujeres frente a ella, como dadoras de vida, como nutridoras, 
como refugio, como bálsamo; estas representaciones parecen generar un respeto capaz de vencer a otras pulsiones.

La figura de la madre lejana tiene para el soldado o el hombre armado un poder especial. En su día, escuché relatar a Jörgen Johansen, presidente entonces de la War Resister's International, cómo durante una visita de un grupo de Observadores Internacionales a Chechenia, en los momentos más duros de su guerra con Rusia, en los controles que dificultaban sus pasos bastaba ofrecer el móvil-satélite para llamar a la madre, para que las voluntades de quienes seguramente habían cometido atrocidades se quebraran y asintieran en dejarles continuar. Otro ejemplo es el que contaba una amiga que vivió en Colombia más de 15 años, cómo en la casa de un paramilitar perpetrador de crímenes sin medida, al que tuvo que visitar en un proceso de mediación, el cuarto de las visitas estaba presidido por una imagen de la Virgen de tamaño natural.

También Cynthia Enloe (1983: 173-174) escribió sobre unas detenidas a las que otras mujeres dan un uniforme de enfermera para protegerlas de la violación por parte de sus captores, cosa que logran (apud Macdonald, 1987: 14-15). En la Guinea Ecuatorial actual, las conversaciones con una ex alumna mía, monja de Santa Ana, allí destinada, me confirman que tener un dispensario abierto a todo aquél que lo necesita, protege a las monjas que se mueven por los peligrosos caminos del país de agresiones y ataques.

La capacidad de estas representaciones de mujeres, sagradas en alguna medida, para servir de freno a la violencia directa, no significa, no obstante, que esta protección actúe de un modo automático y generalizado; no significa que madres, enfermeras, y cuidadoras en general, no hayan sido víctimas de la violencia o sean susceptibles de serlo en alguna circunstancia.

\section{Mujeres como símbolo de la tradición, cargando con el peso de la cultura}

Una versión de la noción de la mujer como símbolo de todo aquello que hay que proteger y por lo que hay que luchar es la que la sitúa como representación de una cultura. Es frecuente que sobre los hombros de las mujeres recaiga el peso del mantenimiento de las tradiciones. A ellas se les exige que sean la representación viva de las identidades culturales: que vistan, vivan y se comporten de acuerdo con la tradición, sin que importe lo demoledor que sea esta sujeción para su libertad individual. En su Carta de una mujer árabe indignada, Wassyla Tamzali muestra su furia ante estas exigencias. Mujeres como ella, que pelearon codo a codo con los hombres para lograr la independencia de su país (Argelia), ven cómo las mujeres vuelven a ser sometidas, cómo se manipula y se utiliza como confrontación cultural la identidad de la mujer, en este caso de la mujer musulmana, una identidad 
"que, como todas las identidades bajo llave (escribe Wassyla) bien podría ser una fortaleza vacía" (Tamzali, 2011: 44). Le indigna que los franceses de origen argelino, acompañados por el relativismo de los intelectuales europeos, dice, reclamen el reconocimiento de su cultura y de su culto, aunque contradigan los derechos de la República y que "con ese espíritu" reivindiquen que sea abolida "la ley contra el velo en la escuela, que califican de racista y de étnica". Todo le confirma algo que ella considera históricamente ya sabido: que "las guerras identitarias se libran siempre sobre el cuerpo de las mujeres. Y ésta es una más" (ibidem: 72).

Para Tamzali, la cultura no es algo petrificado sino la búsqueda de un nosotros que está por hacer, "es lo que me permite no ser lo que soy" (ibidem: 82). Ella propone ejercer el espíritu crítico, por el bien de todos, también de esas

jóvenes francesas, sus congéneres, reducidas a una minoría visible en un país republicano y cuyas posturas étnico-identitarias contribuyen a alimentar los males del racismo, de la exclusión y del miedo al otro y que, además, corren el riesgo de ser devoradas por los signos que utilizan. (ibidem: 73)

\section{Las mujeres como símbolo de paz}

$\mathrm{Al}$ respecto, resumiré dos líneas que recrean la unión mujeres-paz: a) la representación esencialista tradicional que toma a las mujeres como símbolo de paz, de todo aquello que hay que proteger y por lo que hay que luchar, y que hace de la violencia un atributo de los hombres, y b) la que defiende la contradicción en los términos que supone ser madre y combatiente.

La dicotomía mujer pacífica-hombre violento, que naturaliza a hombres y mujeres forma parte de los estereotipos de género, y en otro lugar (Magallón, 2006) he argumentado que su mantenimiento en absoluto favorece la construcción de culturas de paz. La unión esencialista de las mujeres con la paz no se corresponde con la pluralidad de comportamientos de las mujeres de carne y hueso, ni tan siquiera con las que se oponen a la violencia. Revelador de esta distorsión entre imagen, realidad y discurso sobre los hechos, es lo sucedido ante acciones emblemáticas como el campamento de mujeres de Greenham Common, en Inglaterra, iniciado en los años 80. Las acciones y enfoques de estas mujeres, que pelearon contra el despliegue de los euromisiles, fueron percibidas en su día como desconcertantes ya que no encajaban con la imagen de 'mujer pacífica' que el discurso simbólico les asignaba. Lynne Jones recogió los apelativos con los que fueron designadas en la prensa del momento. Y los clasificó según el cuadro siguiente. 
Mujeres de Greenham Common: estereotipos que usó la prensa para hablar de ellas

\begin{tabular}{ll}
\hline \multicolumn{1}{c}{ Positivo } & \multicolumn{1}{c}{ Negativo } \\
\hline Sacrifica el confort del hogar & Abandona a los hijos \\
Vive en condiciones horribles & Vive en la miseria \\
Valiente, comprometida & Sanguinaria, obstinada, agresiva \\
Defiende sus creencias & No admite las derrotas \\
Indumentaria adecuada & No le importa su apariencia \\
No materialista & No le importan las propiedades de los otros \\
Idealista & Ingenua \\
Feminista, lesbiana & Pro-liberación de la mujer, odia a los hombres, \\
& lesbiana \\
Vanguardia del movimiento pacifista & Freno del movimiento pacifista \\
Símbolo de resistencia & Causa perdida \\
Imaginativa & Loca \\
Espiritual & Espiritual \\
Creativa & Quinqui \\
No-violenta & Pasiva \\
Igualitaria & Sin liderazgo \\
Comunal & Desorganizada \\
Rechaza la jerarquía & Caótica, sin estructura \\
Sin líderes & Es manipulada por unas pocas \\
Un grupo pequeño valiente & Una minoría pequeña \\
\hline
\end{tabular}

Fuente: Lynne Jones (1987: 181). Traducción propia

Para Jones esta diversidad de adjetivos, sobre las mismas mujeres y hechos, contradictorios, positivos y negativos, son prueba de que más que en la realidad, las representaciones están en la mente de quien escribe.

La contradicción entre maternidad y violencia ha sido reactivada por filósofas como Sara Ruddick (1989) quien, en su Maternal Thinking, defiende que la dedicación mayoritaria de las mujeres a lo que llama mothering o maternal work ${ }^{1}$ ('trabajo de maternaje') genera una priorización de las vidas que hace a éstas más proclives al rechazo de la violencia. Por mi parte, en otro lugar (Magallón, 2001) he argumentado que de una lectura fiel a las posiciones epistemológicas de Ruddick no se deduce que sea una línea esencialista, pues ella no dice que las mujeres sean más pacíficas, sino que el trabajo de

${ }^{1}$ Mothering, a diferencia de motherbood, se refiere a una práctica, a un trabajo. Para remarcar esta diferencia ya en Magallón (2001), lo traduje como práctica maternal o maternaje. El término 'maternaje' no está en el diccionario de la lengua española: lo adopté de activistas feministas latinoamericanas. 
criar y socializar seres humanos entra en contradicción con el ejercicio de la violencia; caracteriza el maternaje como una práctica - no un factor biológico - que aunque mayoritariamente realizan las mujeres, también pueden realizar, y de hecho realizan, los hombres.

Los estereotipos de género, tal como ha señalado Lígia Amâncio (1993) y en su día, en relación con la violencia, señaló Virginia Woolf (1938), no vienen sólo de miradas externas sino que, como es lógico que suceda en categorías relacionales, hay mujeres que los refuerzan.

\section{Sobre cómo se ven a sí mismas: fortalezas y resistencias}

En guerras y escenarios violentos, las mujeres adoptan múltiples papeles; siguiendo motivaciones diversas, entre las que puede estar la ideología, la supervivencia, el patriotismo o la construcción de una identidad libre, buscan su lugar y se proyectan en roles muy diferentes, ejerciendo una opción propia. Entre las mujeres, siempre ha habido un gran deseo de ser libres y una variedad de comportamientos. No sólo han sido víctimas, esclavas sexuales, pacificadoras o enfermeras, sino que también han tomado las armas, han sido resistentes, patriotas, traidoras a los suyos o escépticas ante el patriotismo... (Elshtain, 1987; Panos Institute, 1995). A muchas les sucedió lo que a algunos veteranos, que su colaboración con la guerra, a través de servicios como la enfermería, les dejó un poso crítico, un poso que devuelven a la sociedad desde una voz propia, a veces lírica, como reflejan los poemas escritos por mujeres que sirvieron en la Guerra de Vietnam (Devanter, 1991).

La rebelión de las mujeres ante el rol asignado es patente en las que fueron victimizadas, y que en algún momento de sus vidas se negaron a seguir siendo reducidas a víctimas pasando a reclamar justicia y reparación. Pienso en las ya nombradas 'mujeres confort' que muchos años más tarde de su explotación sexual tuvieron el coraje de organizarse y reclamar compensaciones: en el 2000, un juicio en Tokio acabaría consiguiendo que el jefe del Gobierno japonés les pidiera perdón. Pienso en Yolanda Aguilar, raptada, violada y amenazada de muerte por sus actividades sindicales, más tarde exiliada, que dedicó su empeño a recoger los nombres de las más de 25000 mujeres violadas en la guerra de su país, Guatemala (Paz and Bailey, 2006).

Como agentes que deciden libremente, en relación con la guerra o la violencia, las mujeres optan por distintos roles, dando lugar a imágenes muy diferentes de las que crecen en el universo simbólico social de dominancia masculina. A continuación señalo, de modo fragmentario, y siempre para seguir pensando, algunos de ellos. 


\section{Mujeres que deciden coger las armas}

Pese a la falta de transmisión histórica, siempre ha habido mujeres que han participado en acciones armadas: en los bandos de las guerras (Saywell, 1987; Panos Institute, 1995; Vickers, 1993), en grupos guerrilleros (Kampwirth, 2007; Vázquez et al., 1996; Ibarra Melo, 2007) y en grupos terroristas (Baños, 2009; Martínez, 2010). Y aunque haya pesado el entorno contextual y familiar, ha sido su propia decisión la que ha contado a la hora de enrolarse.

Los pocos estudios que se han preguntado sobre la participación de las mujeres en las guerrillas y cómo han cambiado sus vidas por ello, han afirmado que así como las motivaciones de hombres y mujeres fueron muy similares -confiesan haberse enrolado "para vivir en países más libres y tener más opciones en la vida” (Kampwirth, 2007: 21)-, la repercusión en sus vidas posteriores fue muy diferente (Vázquez et al., 1996). En América Latina, en las guerrillas de los años 70, del siglo xx, hubo más diferencia de motivación entre las propias mujeres que se unían a la guerrilla: así como en las de procedencia urbana, la ideología les llevaba a dejar situaciones acomodadas y trayectorias de estudios, las mujeres del medio rural, además de la libertad, buscaban en la guerrilla huir de las duras condiciones de vida en el campo (Ibarra Melo, 2007). Hay evidencias de que en los casos de las guerrillas de Nicaragua, El Salvador y Guatemala, la procedencia y estatus de hombres y mujeres era distinta. A diferencia de sus compañeros, "los miles de mujeres que ligaron sus destinos al de las guerrillas eran, más probablemente, de origen urbano y con educación secundaria y universitaria" (Kampwirth, 2007:33).

En el ejército, en las últimas décadas, las mujeres entran como a una profesión más, y son desplegadas en operaciones de todo tipo; en algún país (Israel) son obligadas a realizar el servicio militar, por ley. En enero de 2007, dentro de las operaciones de mantenimiento de la paz de la ONU, en la Misión de Liberia (UNMIL), por primera vez, se desplegó un contingente de policía, constituido en la India, formado íntegramente por mujeres.

La relación de las mujeres con las armas es controvertida. En Estados Unidos, donde la Segunda Enmienda de la Constitución considera su tenencia un derecho, una mayoría de las poseedoras declaran haberse comprado un arma para defenderse; otras lo hicieron para practicar el tiro o cazar (Kelly, 2004). Pero la imagen de una mujer con un arma sigue estando mal vista. Un movimiento importante, la Marcha del Millón de Madres se manifiesta pidiendo más control sobre el comercio de armas. Un millón parecen muchas, pero frente a ellas, la Asociación Nacional del Rifle, con más de cuatro millones de miembros y 133 años de vida, sigue siendo un rival difícil de batir. 
Las vidas plurales de las mujeres corroboran que ellas son tan capaces como los hombres de ejercer violencia, y sólo algún feminismo esencialista lo niega. La mayoría defienden lo que Amelia Valcárcel (1980) acuñó como el "derecho al mal", que por supuesto no equivale a defender el mal mismo. Tal vez la finura y la fragilidad de esta distinción, esté en la base del escaso interés del feminismo por generar auto-imágenes de mujeres guerreras; también la constatación de la capacidad del poder para su manipulación.

\section{Mujeres coraje}

Son mujeres coraje los grupos que pelean contra la impunidad, del tipo Madres de Plaza de Mayo, CONAVIGUA o Viudas de Guatemala, Madres del Salvador, Madres de soldados rusos, y tantas otras que buscan a sus familiares desaparecidos y se enfrentan a dictadores y mafias (Magallón, 2006). Otras buscan sacar de la cárcel a sus maridos o hijos, como las Damas de Blanco, en Cuba; o sobrevivir tras la muerte de sus maridos o compañeros en situaciones de pobreza y soledad (Tovar, 2006); y están también los grupos de Madres contra la droga, que pelean hasta ver detenidos y juzgados a quienes han arruinado la vida de sus hijos o hijas.

\section{Ciberactivistas}

En los últimos tiempos, al hilo de las posibilidades de comunicación global, son notables algunas actuaciones de mujeres que agitan la protesta con sus escritos y llamamientos a través de las redes sociales. Ejercen un liderazgo que encaja muy bien con la tradición no-violenta, ahora virtual. La profesora de inglés en la universidad y bloguera, Lina Ben Mhenni, de Túnez, es una de ellas. Hija de un opositor al régimen tunecino que pasó años en prisión, a sus 28 años participó en la agitación que llevó a los levantamientos de la Primavera árabe; su primer libro, La revolución de la dignidad, se publicó en 2011. Otra bloguera, la egipcia Aliya el Mahdy, escandalizó a los islamistas colgando en la red una foto suya desnuda para llamar la atención y denunciar la situación de las mujeres en su país (Valenzuela, 2012). Y es bien conocido el activismo en la red de la cubana Yoani Sánchez.

\section{Mujeres que construyen la paz}

Constituyen el conjunto de grupos y redes con mayor peso, formando parte de una trayectoria histórica de feminismo internacionalista que nació en el Congreso de La Haya, en 1915 (Magallón, 2012). En él se fundó WILPF: the Women's International League for Peace and Freedom, la organización feminista más veterana del ámbito internacional. Con el tiempo, crecieron otras organizaciones de mujeres en contra de la violencia, las guerras y las 
armas; redes con capacidad de presión e incidencia en la gobernanza global, formando parte de ese feminismo internacionalista que interpela al poder en los distintos niveles, incluidas las estructuras de la ONU. Su influencia en el sistema internacional se ha visto plasmada en la reciente creación de ONU Mujeres y en la aprobación de diversas resoluciones a favor de la participación de las mujeres en los procesos de paz y su protección ante la violencia sexual en los conflictos armados, tendencia que comenzó con la aprobación de la resolución 1325/2000, un hito que ha sido utilizado como inspiración y herramienta (Mesa, 2009) y cuyo logro y puesta en práctica a lo largo de los más de diez años de su existencia ha sido ensalzado y criticado (Mesa, 2010; Santos et al., 2010; Magallón, 2012).

A este feminismo que se mide con el poder, se le puede achacar el no ser todavía capaz de integrar las resistencias más populares, ligadas a identidades invisibilizadas por las miradas hegemónicas (Moura, 2007), no presionar lo suficiente para que los reconocimientos formales den lugar a políticas reales, que mejoren las vidas de las que viven en los lugares más difíciles. Uno de los objetivos perseguidos, dar más peso a las voces de las mujeres en los procesos de paz, hasta ahora, ha sido reconocido como derecho, pero los resultados prácticos son todavía escasos (Villellas, 2010).

Las fortalezas de las mujeres se proyectan también en la acción de múltiples grupos de base que desafían a sus gobiernos y se unen por encima de las barreras que enfrentan a sus grupos de pertenencia; a partir de visiones y estrategias propias, buscan presionar e influir en el cambio de mentalidad, los discursos sociales y la toma de decisiones, ofreciendo alternativas para la convivencia (VVAA, 1996; Cockburn, 1998, 2004 y 2009; Farhat-Naser, 2006; Magallón, 2006; Grau, 2010). El simbolismo de sus acciones, busca desmontar la violencia de las representaciones. Dado que

... las imágenes trabajan en un nivel menos fácil de articular son difíciles de cuestionar, pues el 'lenguaje' dominante de cuestionamiento es más evidente y menos complejo que el de las imágenes subyacentes. Es por eso por lo que las mujeres han tenido que desarrollar el cuestionamiento del status quo no sólo a través de argumentos racionales "objetivos", sino también a través del simbolismo y la subversión de las propias imágenes. (McDonald, 1987:3)

\section{Conclusiones}

Partiendo de que todo conocimiento es situado, la epistemología del Feminist Standpoint, reafirma la importancia de situarse a pensar desde las vidas de las mujeres, para tomar en consideración aspectos antes no tenidos en cuenta por el conocimiento androcéntrico. En relación con la violencia, es posible 
ver cómo determinadas representaciones desencadenan comportamientos contextuales que desembocan en violencias específicas contra ellas; también ver la diversidad de comportamientos de éstas, sus fortalezas y resistencias en contextos de violencia. El contraste entre las viejas representaciones heteroconstruidas, ancladas en los estereotipos, y la pluralidad de vías por las que optan las mujeres, abre discursos de libertad y es una crítica a los persistentes nichos de violencia con marca de género.

\section{Bibliografía}

Amâncio, Lígia (1993), "Género-representações e identidades", Sociologia-Problemas e Práticas, 14, 127-140.

Baños, Pedro (2009), “Análisis de los atentados suicidas femeninos”, Documentos de Trabajo (DT 17/2009), Real Instituto Elcano. Consultado en 30.03.2012, en http://bit. ly/Halyl2.

Butler, Judith (2006), Vida precaria. El poder del duelo y la violencia. Buenos Aires: Paidós (Trad. Fermín Rodríguez).

Butler, Judith (2010), Marcos de guerra. Las vidas lloradas. Barcelona: Paidós (Trad. Fernando Moreno Carrillo).

Cockburn, Cynthia (1998), The Space Between Us: Negotiating Gender and National Identities in Conflict. London: Zed Books.

Cockburn, Cynthia (2004), The Line: Women, Partition and the Gender Order in Cyprus. London: Zed Books.

Cockburn, Cynthia (2009), Mujeres ante la guerra: desde donde estamos. Barcelona: Icaria (Trad. Griselda Piñero).

Devanter, Lynda Van (1991), Visions of War, Dreams of Peace. Writings of Women in the Vietnam War. New York: Warner Books.

Díez Jorge, María Elena (2010), "Género y paz a través del arte: memorias y silencios construidos”, in María Elena Díez Jorge y Margarita Sánchez Romero (orgs.), Género y paz. Barcelona: Icaria, 129-149.

Elshtain, Jean (1987), Women and War. Chicago: University of Chicago Press.

Enloe, Cynthia (1983), Does Khaki Become You? The Militarisation of Women's Lives. London: Pluto Press.

Enloe, Cynthia (1989), Bananas, Beaches and Bases: Making Feminist Sense of International Politics. Berkeley: University of California Press.

Farhat-Naser, Sumaya (2006), En la tierra de los olivos. Una bistoria de mujeres por la paz. Barcelona: El Aleph (Trad. Anna Tortajada).

Galtung, Johan (2003), Paz por medios pacíficos. Paz y conflicto, desarrollo y civilización. Oslo: PRIO (Trad. Teresa Toda).

Goldstein, Joshua S. (2001), War and Gender: How Gender Shapes the War System and Vice Versa. Cambridge: Cambridge University Press. 
Grau, Elena (1993), “Vivir en un cuerpo violable”, En pie de paz, n. ${ }^{\circ} 28$, p. 47.

Grau, Elena (2010), "Dones constructores de pau: invisibilitat i presencia”, Per la Pau. Peace in Progress, Revista electrónica del ICIP, 6. Consultado en 15.04.2012, en http://bit.ly/H470A0.

Harding, Sandra (1986), The Science Question in Feminism. New York: Cornell University Press.

Harding, Sandra (1991), Whose Science? Whose Knowledge? Thinking from Women's Lives. New York: Cornell University Press.

Ibarra Melo, Maria Eugenia (2007), Transformaciones identitarias de las mujeres como resultado de su participación política en las guerrillas y en las acciones colectivas por la paz en Colombia, Tesis dirigida por la Dra. Concepción Fernández Villanueva, Univ. Complutense, Madrid.

Jones, Lynne (1987), “Perceptions of 'Peace Women’ at Greenham Common 1981-85: A Participant's View”, in Sharon Macdonald et al. (orgs.), Images of Women in Peace and War. Cross-Cultural and Historical Perspectives. London: MacMillan Education, 179-204.

Kaldor, Mary (2001), Las nuevas guerras. Violencia organizada en la era global. Barcelona: Tusquets.

Kampwirth, Karen (2007), Mujeres y movimientos guerrilleros. Nicaragua, El Salvador, Chiapas y Cuba. México D.F.: Plaza y Valdés.

Kelly, Caitlin (2004), Blown Away. American Women and Guns. New York: Pocket Books.

Lindqvist, Sven (2004), Exterminad a todos los salvajes. Madrid: Turner.

López Insausti, Rafael; Baringo, David (2006), Nadie va de putas. El hombre y la prostitución femenina. Zaragoza: Organización Editorial S.L.

Macdonald, Sharon; Holden, Pat; Ardener, Shirley (1987), Images of Women in Peace and War. Cross-Cultural and Historical Perspectives. London: MacMillan Education.

Magallón Portolés, Carmen (1998), "Sostener la vida, producir la muerte: estereotipos de género y violencia”, in Vicenç Fisas (org.), El sexo de la violencia. Barcelona: Icaria-Antrazyt, 93-116.

Magallón Portolés, Carmen (1999), "Privilegio epistémico, verdad y relaciones de poder. Un debate sobre la epistemología del feminist standpoint”, in María José Barral; Carmen Magallón Portolés; Consuelo Miqueo y Dolores Sánchez (orgs.), Interacciones ciencia y género: discursos y prácticas cientificas de mujeres. Barcelona: Icaria-Antrazyt, 63-80.

Magallón Portolés, Carmen (2001), "El pensamiento maternal. Una epistemología feminista para una cultura de paz”, in Francisco A. Muñoz (org.), La paz imperfecta. Granada: Universidad de Granada, colección Eirene, n 15, 123-141.

Magallón Portolés, Carmen (2002), "Mujeres en las guerras, mujeres por la paz", in María Elósegui, Teresa González y Concha Gaudó (orgs.), El rostro de la violencia. Más allá del dolor de las mujeres. Barcelona: Icaria, 81-102. 
Magallón Portolés, Carmen (2005), "Epistemología y violencia. Aproximación a una visión integral sobre la violencia hacia las mujeres", Feminismo/s, revista del Centro de Estudios sobre la Mujer de la Universidad de Alicante, $n^{\circ}$ 6, 33-47.

Magallón Portolés, Carmen (2006), Mujeres en pie de paz. Madrid: Siglo XXI.

Magallón Portolés, Carmen (2012), Contar en el mundo. Una mirada sobre las Relaciones Internacionales desde las vidas de las mujeres. Madrid: Horas y horas.

Martínez Varela, Estefanía (2010), El fenómeno de la mujer terrorista suicida. Instituto Universitario General Gutiérrez Mellado. Consultado en 30.03.2012 en http://iugm. es/uploads/tx_iugm/Estefania_Martinez_Varela.pdf.

Mesa, Manuela (2010), “Mujer, paz y seguridad: la resolución 1325 en su décimo aniversario", in M. Mesa (coord.), Balance de una década de paz y conflictos: tensiones y retos en el sistema internacional, Anuario 2010-2011. CEIPAZ y Fundación Cultura de Paz. Barcelona: Icaria, 43-64.

Mesa, Manuela y Alonso, Laura (coords.) (2009), 1325 mujeres tejiendo la paz. Barcelona: Icaria.

Mirón Pérez, María Dolores; Martínez López, Cándida; Díez Jorge, María Elena; Sánchez Romero, Margarita y Martín Casares, Aurelia (2004), Las mujeres y la paz: génesis y evolución de conceptualizaciones, simbolos y prácticas. Madrid: Instituto de la Mujer.

Moura, Tatiana (2007), Rostos invisíveis da violência armada. Um estudo do caso sobre $o$ Rio de Janeiro. Rio de Janeiro: Letras.

Moura, Tatiana (2010), Novíssimas guerras. Espaços, identidades e espirais da violência armada. Coimbra: Almedina.

Moura, Tatiana (2012), "Factores de violencia y de pacificación en las aglomeraciones urbanas”, in Fundación SIP (org.), Las paces de cada día. Zaragoza: Dpto. de Educación y Cultura, Gobierno de Aragón, en prensa.

Panos Institute (1995), Armas para luchar, brazos para proteger. Las mujeres bablan de la guerra. Barcelona: Icaria.

Paz, Claudia; Bailey, Paz (2006), "Guatemala: Gender Reparations for Human Right Violations", in Ruth Rubio-Marín (org.), What happened to the Women? Gender and Reparations for Human Rights Violations. New York: Social Science Research Council, 92-135. Versión electrónica accessible en http://bit.ly/yzHwGa.

Reardon, Betty (1996), Sexism and the War System. New York: Syracuse University Press.

Ruddick, Sara (1989), Maternal Thinking: Toward a Politics of Peace. London: The Women Press.

Santos, Rita; Moura, Tatiana y Roque, Silvia (2010), "UNSCR 1325: It is Only about War? Armed Violence in Non-War Contexts", Oficina do CES, 340.

Santos, Rita (2009), "Disarming Domestic Violence in Portugal”. Entrevista por Aaron Fuchs, consultada en 18.03.2012, en http://www.youtube.com/watch?v=Uk_kdyacuoc. 
Saywell, Shelley (1987), Women in War. First Hand Accounts from World War II to El Salvador. Great Britain: Costello.

Tamzali, Wassyla (2011), Carta de una mujer indignada. Desde el Magreb a Europa. Madrid: Cátedra, Feminismos.

Tickner, J. Ann (1992), Gender in International Relations: Feminists Perspectives on Achieving Global Security. New York: Columbia University Press.

Tickner, J. Ann (2006), "Feminism Meets International Relations: Some Methodological Issues”, in Brooke A. Ackerly; Maria Stern y Jacqui True (orgs.), Feminist Methodologies for International Relations. Cambridge: Cambridge University Press, 19-41.

Tovar Rojas, Patricia (2006), Las viudas del conflicto armado en Colombia. Memorias y relatos. Bogotá: Instituto Colombiano de Antropología e Historia, Colciencias.

VVAA (1996), Mujeres por la Paz. Belgrado: Zene u Crnom.

Valcárcel, Amelia (1980), "El derecho al mal", El viejo Topo (artículo incluido en: Sexo y filosofía, Barcelona: Anthropos, 1991).

Valenzuela, Javier (2012), “Desencanto árabe 2.0”, El País, domingo 4 de marzo, 5-7.

Vázquez, Norma; Ibáñez, Cristina y Murguialday, Clara (1996), Mujeres-Montaña. Vivencias de guerrilleras y colaboradoras del FMLN. Madrid: Horas y Horas.

Vickers, Jeanne (1993), Women and War. London: Zed Books.

Villellas Ariño, María (2010), "The Other Tables. The Participation of Women in Peace Processes”, ICIP Working Paper, 5.

Whistleblower, The (film), consultado en 20.03.2012, en http://bit.ly/Hrb9Dm.

Woolf ,Virginia (1938), Tres Guineas. Barcelona: Lumen, 1977.

Women's Tribunal 2000, “Violence against Women in War-Network Japan”, consultado en 21.03.2012, en http://bit.ly/Ha46ZT.

Youngs, Gillian (2004), "Feminist International Relations: A Contradiction in Terms? Or Why Women and Gender are Essential to Understand the World 'We' Live in", International Affairs, 80(1), 75-87. 
